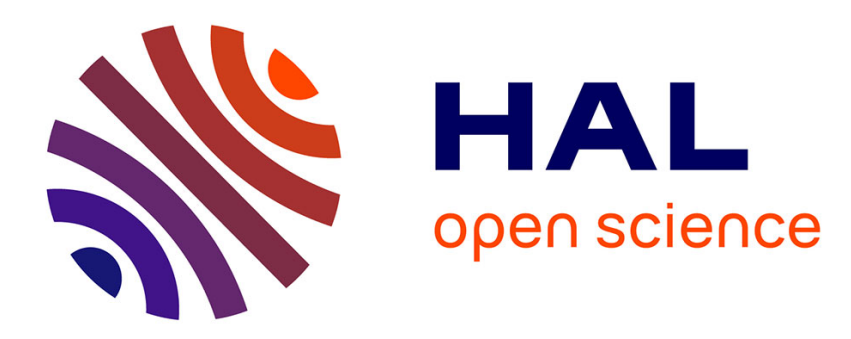

\title{
Tension éthique autour des classifications dites raciales en anthropologie
}

\author{
A. Andry, P. Charlier
}

\section{To cite this version:}

A. Andry, P. Charlier. Tension éthique autour des classifications dites raciales en anthropologie. Ethics, Medicine and Public Health, 2019, 8, pp.22 - 29. 10.1016/j.jemep.2018.11.001 . hal-03484532

\section{HAL Id: hal-03484532 \\ https://hal.science/hal-03484532}

Submitted on 21 Dec 2021

HAL is a multi-disciplinary open access archive for the deposit and dissemination of scientific research documents, whether they are published or not. The documents may come from teaching and research institutions in France or abroad, or from public or private research centers.
L'archive ouverte pluridisciplinaire HAL, est destinée au dépôt et à la diffusion de documents scientifiques de niveau recherche, publiés ou non, émanant des établissements d'enseignement et de recherche français ou étrangers, des laboratoires publics ou privés.

\section{다)(1) $(5$}

Distributed under a Creative Commons Attribution - NonCommerciall 4.0 International 
An engine-relevant kinetic investigation into the anti-knock effect of organometallics through the example of ferrocene

Y. Fenard ${ }^{1}$, H. Song ${ }^{1}$, R. Dauphin ${ }^{2}$, G. Vanhove ${ }^{1}$

${ }^{1}$ Univ. Lille, CNRS, UMR 8522 - PC2A - Physicochimie des Processus de Combustion et de l'Atmosphère, F-59000 Lille, France

${ }^{2}$ Total Marketing Services, Centre de Recherche de Solaize, Chemin du Canal - BP 22, 69360 Solaize France

\section{Corresponding author:}

Guillaume Vanhove

PC2A

Bâtiment C11, Université de Lille, Cité Scientifique, Avenue Mendeleiev, 59650 Villeneuve-d'Ascq, France

Phone: +33 320434485, Fax: +33 320436977, E-mail : guillaume.vanhove@univ-lille.fr

Colloquium: Gas-Phase Reaction Kinetics

Paper length: $\quad \operatorname{Text}(/$ Word processor $)=$

(figure height in $\mathrm{mm}+10 \mathrm{~mm}) \times(2.2$ words $/ \mathrm{mm}) \times$ (\#columns $)+($ \#words in caption)

$=[54+10 \times 2.2 \times 1+23=164]+[54+10 \times 2.2 \times 1+0=141]+[54+10 \times 2.2 \times 1+29=170]$

$+[54+10 \times 2.2 \times 1+0=141]+[54+10 \times 2.2 \times 1+36=177]+[54+10 \times 2.2 \times 1+23=164]$

$+[54+10 \times 2.2 \times 1+0=141]+[54+10 \times 2.2 \times 1+29=170]+[54+10 \times 2.2 \times 1+0=141]$

$+[54+10 \times 2.2 \times 1+36=177]+[54+10 \times 2.2 \times 1+0=141]+[54+10 \times 2.2 \times 1+24=165]$ 


\title{
Abstract length $=\quad 222$ words
}

\begin{abstract}
A detailed study on the ignition of ferrocene-containing mixtures has been undertaken in a Rapid Compression Machine (RCM). Two hydrocarbon fuels, isooctane and 3-hexene, were investigated in order to assess the hypothesis of an inhibiting effect of iron oxide particles on $\mathrm{HO}_{2}$ radicals and $\mathrm{H}_{2} \mathrm{O}_{2}$. Ignition delays were measured at core gas temperatures of $700 \mathrm{~K}$ and $850 \mathrm{~K}$, pressures from 6 to 20 bar, and ferrocene mole fractions in the original fuel from 0 to $900 \mathrm{ppm}$. These experiments provide insight into the kinetics of the antiknock effect of ferrocene on both the non-octane sensitive (isooctane) and octane sensitive (3-hexene) fuels.

Experimental results show that doping reactive mixtures with ferrocene always lengthens the total ignition delay. Also, the increment in auto-ignition delay is monotonic with increasing amount of ferrocene while no loss of effectiveness was noticed, even at the highest mole fractions. On the other hand, in the event of two stage ignition, the first stage delay is not affected by any doping with ferrocene. The kinetic mode of action of ferrocene is investigated, based on these statements, in an effort to better understand the impact of organometallic octane boosters on the combustion of fuels.
\end{abstract}

A kinetic short sub-mechanism was built in order to describe the influence of ferrocene on the reactivity of isooctane and 3-hexene in a RCM, yielding qualitative agreement.

Keywords: ignition delay, rapid compression machine, kinetics, ferrocene, anti-knock octane boosters 


\section{Introduction}

The use of organometallics as anti-knock agent goes back to the 1920s, when it was pointed out that TetraEthyl Lead (TEL) had a beneficial effect on preventing knock in Spark Ignition (SI) engines. With the emergence of three-way exhaust catalyst, TEL has been gradually banned from commercial petrol fuels due to its poisoning effect on catalysts, but remains at use for limited applications, such as aviation [1]. As an effort to replace this anti-knock agent, several organometallic octane boosters were used, among which are methylcyclopentadienyl manganese tricarbonyl and ferrocene.

Ferrocene is an organometallic molecule, synthesized for the first time in the 1950's. Ferrocene, or bis $\left(\eta^{5}-\right.$ cyclopentadienyl)iron, also draws its name from its structure: an iron atom between two cyclopentadienyl groups. Ferrocene is an efficient anti-knock octane booster which is cost-competitive and miscible in gasoline but not in water. However, its extensive use in SI engines causes an iron deposit on the spark plug, thus decreasing the insulation resistance of spark plugs which causes spark plug dysfunction, leading to increased fuel consumption and exhaust emissions. Nevertheless, ferrocene is still being used in several countries, and might be used in high-performance engines. Moreover, the mechanism responsible for its octane-boosting effect can also be relevant for other organometallic additives.

Most experimental studies on the effect of ferrocene on combustion relate to flame studies. For example, the soot-inhibiting characteristics of ferrocene have been demonstrated in several conditions. Bonczyk [2] noticed that the doping of isooctane/air diffusion flames with ferrocene enhances the soot burn out, without affecting the flame temperature. This was confirmed by several studies, with various fuels and experimental setups: Crude oil pool fires [3], laminar, coannular, ethylene/air non-premixed flames [4,5], heavy-duty diesel engines [6], acetylene diffusion flames [7], and ethylene diffusion flames [8]. All conclude that carbonaceous compounds condense at the surface of iron oxide nuclei formed during the early stage of the flame, followed by burn out during the last stage of combustion. The critical sooting $\mathrm{C} / \mathrm{O}$ ratio was measured by Hirasawa et al. [9] for laminar premixed ethylene flames, concluding in a marked increase in the sooting tendency for flames doped with ferrocene. A five-step reaction mechanism of ferrocene decomposition, leading to the formation of the cyclopentadienyl, was proposed, suggesting that the contribution to aromatics formation and growth of the cyclopentadienyl groups in the ferrocene molecule is insignificant.

Linteris et al. [10-12] studied the catalytic inhibition of laminar flames by organometallic compounds through several studies, complemented by a review of the literature. These works point out the reduction of 
the burning velocity of premixed methane flames with addition of ferrocene or iron pentacarbonyl, with a reduced effect at mole fractions above a few hundred ppm. From these studies, a detailed kinetic submechanism for the oxidation of ferrocene was suggested, based on the previous modeling work of Rumminger et al. [13] on iron pentacarbonyl. The chemical structure of a premixed propene/air flame was investigated by Tian et al. [14]. The influence of iron-containing additives on the measured hydrocarbon intermediates concentrations is small, but a decrease of the flame temperature by $40 \mathrm{~K}$ was observed. These experimental results were simulated using the model built by Linteris et al. [10] with reasonable success. Recently, Zhu et al. [15] studied the kinetic effect of gaseous iron atoms on the ignition and combustion of $n$-heptane with a detailed model based on the work by Linteris et al. [10], at $\mathrm{T}=800 \mathrm{~K}$ and $p=50$ bar. Their work was a modeling effort, with no experimental data available to evaluate the effect of iron on the ignition delay of heptane $/ \mathrm{O}_{2} /$ inert mixtures, and predicted a reduction of the ignition delay time when a concentration of 100 ppm of gaseous iron atom is added. This conclusion is however surprising, given the well-known effect of ferrocene on knock resistance of fuels. A widely accepted hypothesis suggests that metallic oxides particles formed from organometallics act as scavengers for $\mathrm{HO}_{2}$ and $\mathrm{H}_{2} \mathrm{O}_{2}$ (see, for example, [16]). This has however never been experimentally demonstrated. Considering the relevance of Low Temperature Combustion (LTC) mechanisms to the knock phenomenon in Spark-Ignition engines, a kinetic study of the effect of ferrocene on ignition in low temperature and high pressure conditions has therefore the potential to provide insight into the mechanisms of knock inhibition by organometallic octane boosters.

In this study, ignition delay times of fuel/air mixtures doped with ferrocene have therefore been measured, using two fuels with differing ignition kinetics. Isooctane is a non octane-sensitive, branched alkane primary reference fuel, with important LTC reactivity and two-stage ignition [17,18]. 3-Hexene is an octane-sensitive fuel $(\mathrm{RON}=94, \mathrm{MON}=80[19])$ representative of olefin reactivity in gasolines. $\mathrm{HO}_{2}$ radicals have an increased importance in its limited LTC reactivity, mostly because of the additional reaction pathways associated with the $\mathrm{C}=\mathrm{C}$ double bond $[19,20]$. The target mole fraction of ferrocene was from 0 to $900 \mathrm{ppm}$ in the fuel. The temperatures, $700 \mathrm{~K}$ and $850 \mathrm{~K}$, are representative respectively of the low temperature and the negative temperature coefficient region. The pressure ranged from 6 to 20 bar.

\section{Experimental section}


The ULille rapid compression machine, extensively described in the past $[17,21,22]$, has a right angle configuration. A translating cam transmits the movement of the driving piston to the compression piston which compresses the gaseous mixture in the combustion chamber. At the end of the compression, the cam profile prevents the compression piston from bouncing backwards. Furthermore, this design ensures strict control over the piston velocity history during compression.

Solutions were prepared by dissolving a mass of solid ferrocene in the investigated liquid fuels (isooctane, and trans-3-hexene, $>99.8 \%$, Sigma Aldrich). The said solutions were then fully evaporated in heated glass vessels $\left(90^{\circ} \mathrm{C}\right)$, and high purity oxygen, nitrogen and argon $(>99.99 \%$, Air Liquide) were added to form the gaseous mixtures with an inert-to-oxygen ratio of 3.78. Dissolution of ferrocene into liquid isooctane or 3hexene, and successive dilutions, results in an actual concentration of 322, 632 and 924 ppm for isooctane $/ \mathrm{O}_{2} /$ inert mixtures and 306, 607 and $909 \mathrm{ppm}$ for 3-hexene $/ \mathrm{O}_{2} /$ inert mixtures. We report an uncertainty of $1 \%$ on the mole fraction of ferrocene in those mixtures. The partial pressures of each component are measured by heated pressure gauges (0-100 and 1000 torr, MKS Baratron), avoiding condensation on their surface. Pure nitrogen and argon are used as inert gases to reach core gas temperatures $\mathrm{T}_{\mathrm{c}}$ of 700 and $850 \mathrm{~K}$ respectively. Minor adjustments to the initial temperature of the combustion chamber were made to reach the target compressed temperatures. $T_{c}$ is calculated from the initial and compressed pressures and initial temperature using the isentropic law, showing a deviation from the target temperatures inferior to $5 \mathrm{~K}$. The mixture is introduced into the combustion chamber through a heated line $\left(90^{\circ} \mathrm{C}\right)$ in order to avoid condensation. The combustion chamber is surrounded by temperature-controlled heating elements, ensuring a $1 \mathrm{~K}$ deviation along the axial dimension. The RCM, mixture preparation facility and gas lines temperatures were chosen so that the ferrocene partial pressure was inferior to its vapor pressure by a factor of two in all cases [23]. The volumetric compression ratio is 9.65 , the compression time being set to $60 \mathrm{~ms}$ to minimize fluid motion and mechanical vibration after compression [21]. Following the suggestion by Lee and Hochgreb [24], a creviced piston head is used to limit the formation of the piston corner vortex. Pressure profiles in the chamber are recorded with a piezoelectric transducer protected from thermal shock (Kistler 6052). The piston position and pressure are recorded with a $40 \mu$ s time step using a National Instruments acquisition card and LabView. The first stage and total ignition delays are defined as the time elapsed between the top dead center time and the maximum of the time derivative of the pressure associated with firststage ignition and final ignition, respectively. Only ignition delays between 2 and $200 \mathrm{~ms}$ are reported here, 
to accommodate with the measurable test times in this experimental device. All reactive shots are reported to provide information on the reproducibility of the experimental data. To control for possible surface contamination by iron oxides, the ignition delays of isooctane were measured before, after the ferrocene experiments, and finally after a thorough cleaning of the chamber walls, yielding similar results. The results for pure isooctane and 3-hexene were compared to previous data $[20,25]$ obtained with the same RCM, using a flat piston, yielding comparable results.

\section{Results and discussion}

\section{Isooctane}

Ignition delays of stoichiometric isooctane $/ \mathrm{O}_{2} /$ inert mixtures, with various amounts of added ferrocene, were obtained for pressure ranging from 10 to 20 bar at $T_{C}=700 \mathrm{~K}$ and $850 \mathrm{~K}$. First stage ignition is observed at $\mathrm{T}_{\mathrm{C}}=700 \mathrm{~K}$, as presented in Fig. 1 with typical two-stage ignition behavior. The first stage ignition delay, in Fig. 1, decreases very slightly, but in a reproducible way, as the mole fraction of ferrocene increases. It is accompanied with a reduction of the amplitude of the pressure jump associated with first-stage ignition. Figure $2 \mathrm{a}$ illustrates the modification of the ignition delays over the whole pressure range. Simultaneously, the second stage -or time period between first stage and final ignition- increases. Overall, the total ignition delay therefore increases as the ferrocene content increases. 


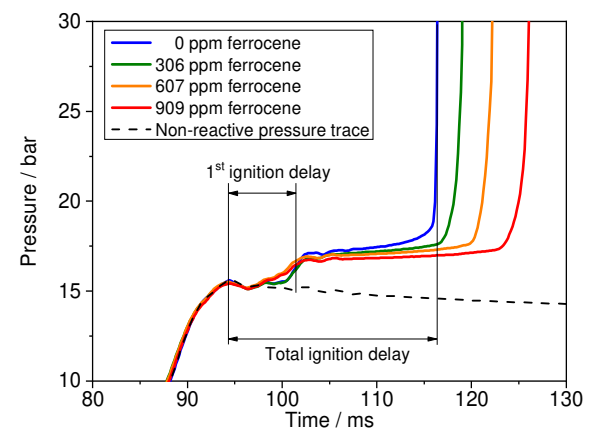

Figure 1: Pressure profiles during the two-stage ignition of isooctane/ferrocene/synthetic air mixtures and associated non-reactive pressure trace. $\Phi=1, p_{\mathrm{TDC}}=1.56 \mathrm{MPa}, \mathrm{T}_{\mathrm{C}}=700 \mathrm{~K}$.

The competition between chain-propagating and chain-branching pathways determines the timing of ignition [26]. Low temperature chain-branching results from the formation and thermal decomposition of ketohydroperoxides, which causes the formation of two $\mathrm{OH}$ radicals that promote the reactivity. This in turn leads to a cool flame or first-stage ignition. The fact that ferrocene has little to no effect on the first-stage ignition delay could result from the absence of iron oxide particles before the cool flame, as well as limited activity of these particles on $\mathrm{OH}$ radicals. However, possible $\mathrm{OH}$ formation pathways involved in the conversion of ferrocene to iron oxides could explain the slight reduction of the first stage ignition delay.
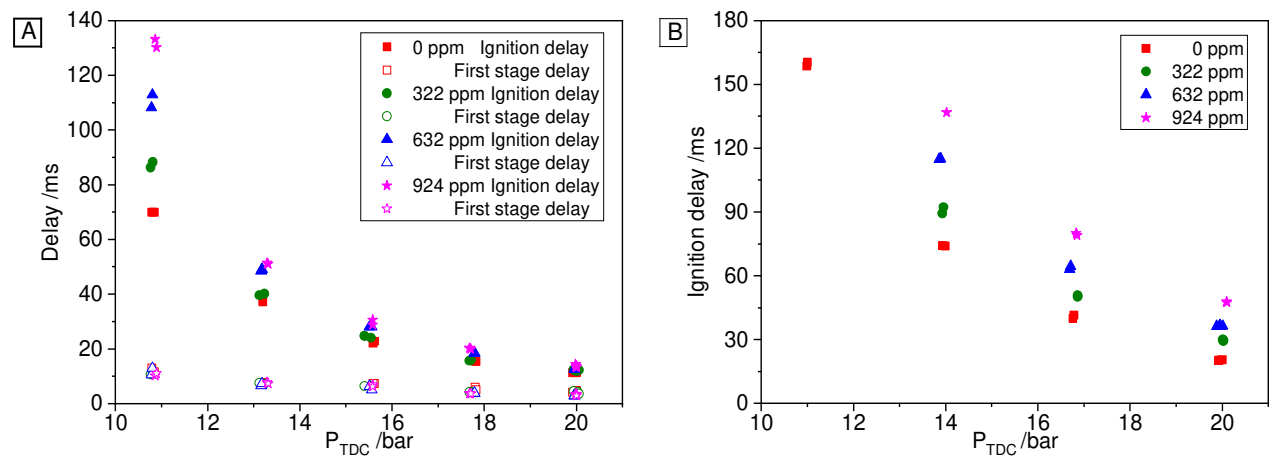

Figure 2: Evolution of total ignition delays as a function of pressure for isooctane/ferrocene/ $\mathrm{O}_{2} / \mathrm{Ar}$ mixtures.

$$
\Phi=1,(\mathrm{~A}) \mathrm{T}_{\mathrm{C}}=700 \mathrm{~K} ;(\mathrm{B}) \mathrm{T}_{\mathrm{C}}=850 \mathrm{~K}
$$

Ignition delays obtained at $700 \mathrm{~K}$ and $850 \mathrm{~K}$ are shown in Fig. $2 \mathrm{a}$ and $2 \mathrm{~b}$ respectively at all investigated ferrocene compositions. The increase of the ignition delay by ferrocene addition is visible for all pressure conditions, but more intense at the lowest pressures at $700 \mathrm{~K}$. In RCM experiments, second-stage ignition is 
related to the temperature history of the mixture during the ignition delay, and is therefore caused by intermediate temperature radical branching. In a simplified approach, the ignition event can be correlated with the brutal consumption of $\mathrm{H}_{2} \mathrm{O}_{2}$ giving two $\mathrm{OH}$ radicals through reaction (R1):

$$
\mathrm{H}_{2} \mathrm{O}_{2}(+\mathrm{M})=\mathrm{OH}+\mathrm{OH}(+\mathrm{M})
$$

The duration of the second stage is thus affected by the concentration of $\mathrm{HO}_{2}$ radicals, an important source of $\mathrm{H}_{2} \mathrm{O}_{2}$, as well as the temperature and pressure after first stage ignition. It is also true for single-stage ignition at $850 \mathrm{~K}$, where ignition depends solely on intermediate temperature branching. Any source of consumption of $\mathrm{HO}_{2}$ and $\mathrm{H}_{2} \mathrm{O}_{2}$ will then increase the second stage of the ignition delay. These experimental results therefore are in agreement with the description of the anti-knock effect of TEL by Pitz and Westbrook [16], through consumption of $\mathrm{HO}_{2}$ radical and $\mathrm{H}_{2} \mathrm{O}_{2}$ onto the surface of lead oxides particles. Indeed, ferrocene will rapidly produce iron oxide particles following attack by the radical pool, with diameters in the order of magnitude of the nanometer [27].
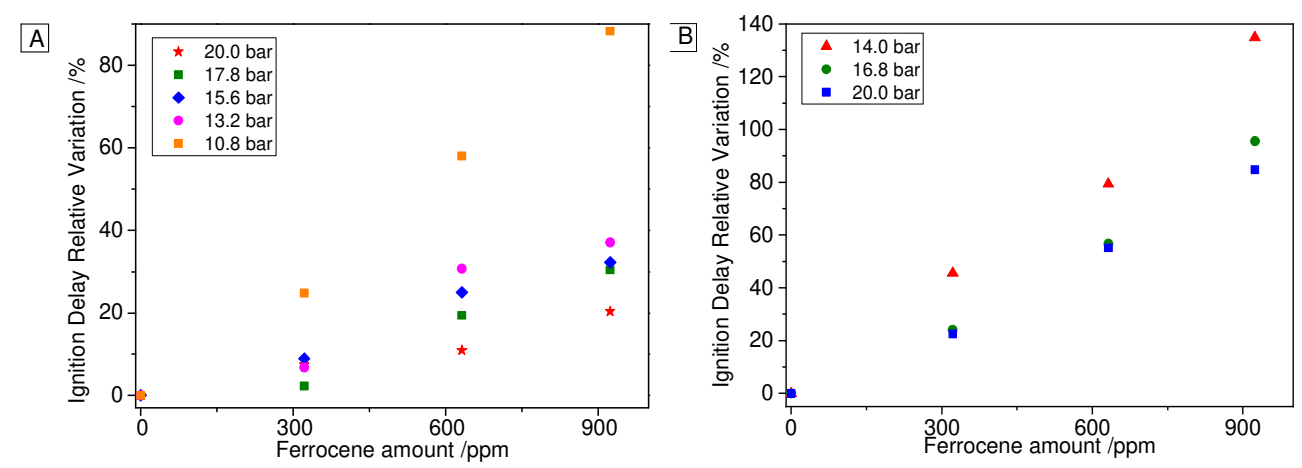

Figure 3: Relative variation of the ignition delay due to ferrocene addition to isooctane as a function of the compressed pressure $p_{\text {TDC. }} \Phi=1$. (A) $\mathrm{T}_{\mathrm{C}}=700 \mathrm{~K}$, (B) $\mathrm{T}_{\mathrm{C}}=850 \mathrm{~K}$.

In Fig. 3, the evolution of relative ignition delay variation with ferrocene addition is presented. A monotonic increment of the ignition delay can be observed. When $p_{\mathrm{TDC}}$ decreases, the duration of the second stage increases as the reaction rate of (R1) decreases. This could explain the superior effect of ferrocene observed at the lowest investigated pressures. 
In order to evaluate the accepted mechanism of the anti-knock effect of organometallics, a similar study was undertaken using 3-hexene. This fuel has higher octane sensitivity than isooctane, very different phenomenology of ignition, associated with additional reaction pathways specific to the double bond. These pathways include addition reactions of radicals to the double bond $[19,28]$, of which $\mathrm{HO}_{2}$ reactions have been identified as particularly important in the low temperature, high pressure oxidation of short alkenes in RCMs [29]. Because of the central position of the double bond in the 3-hexene molecule, it is expected that these pathways are also of great importance in this case.

Figure 4 shows a comparison of the pressure profile at $\mathrm{T}_{\mathrm{C}}=700 \mathrm{~K}$ for all ferrocene compositions. Limited pressure increase is observable right before ignition, due to limited heat release from LTC reactivity, as previously experimentally observed and predicted from kinetic modeling [19,20]. As for isooctane, ferrocene addition increases the ignition delay of 3-hexene.

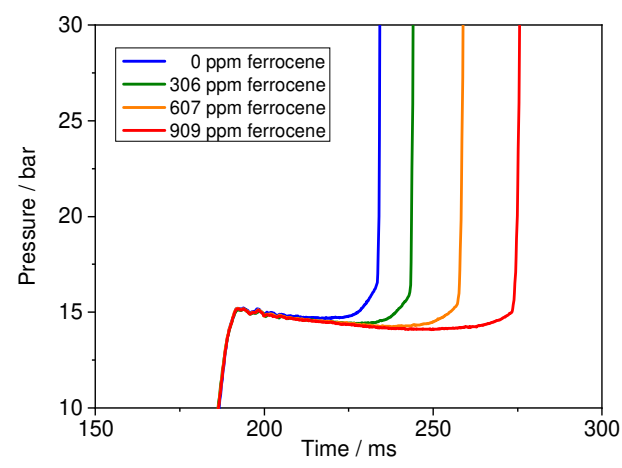

Figure 4: Pressure profiles during the ignition of 3-hexene/ferrocene/synthetic air mixtures. $\Phi=1, p_{\mathrm{TDC}}=$

$$
1.52 \mathrm{MPa}, \mathrm{T}_{\mathrm{C}}=700 \mathrm{~K} .
$$

The effect of ferrocene is visible at all pressures for both $\mathrm{T}_{\mathrm{C}}=700$ and $850 \mathrm{~K}$, as shown in Figs. $5 \mathrm{a}$ and $\mathrm{b}$. The increase of ignition delay is monotonic with ferrocene addition without any evidence of saturation (Figs. $6 a$ and $6 b)$. The relative increase of the ignition delay is visible at both investigated temperatures and superior than in the case of isooctane, reaching values of about $200 \%$ at 20 bar. 

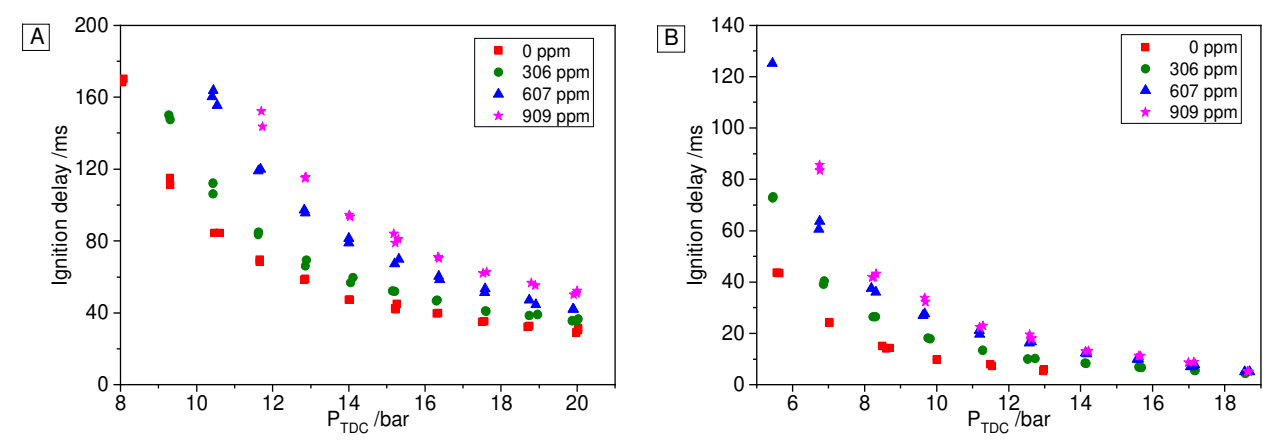

Figure 5: Evolution of total ignition delays as a function of pressure for 3-hexene/ferrocene $/ \mathrm{O}_{2} / \mathrm{Ar}$ mixtures.

$$
\Phi=1,(\mathrm{~A}) \mathrm{T}_{\mathrm{C}}=700 \mathrm{~K} .(\mathrm{B}) \mathrm{T}_{\mathrm{C}}=850 \mathrm{~K} .
$$

The increased effect of ferrocene in the case of 3-hexene can originate from the additional pathways of radical addition to the double bond. The addition of $\mathrm{OH}$ is usually followed by the addition of the resulting hydroxyalkyl radical to $\mathrm{O}_{2}$, yielding two aldehydes and an $\mathrm{OH}$ radical through the so-called Waddington mechanism [30]. The addition of $\mathrm{HO}_{2}$ to the double bond in turn yields a hydroperoxyalkyl radical that can undergo fast decomposition to an oxirane and an $\mathrm{OH}$ radical as previously observed in RCM sampling studies [20,31]. The addition of $\mathrm{HO}_{2}$ to an allylic radical will result in the formation of a carbonyl and $\mathrm{OH}$, or an unsaturated alkoxy radical and $\mathrm{H}_{2} \mathrm{O}$. These pathways are particularly important to predict the global reactivity of the fuel [29], as they form a reactive $\mathrm{OH}$ radical from a relatively unreactive radical $\mathrm{HO}_{2}$. Moreover, the branching pathways described for alkanes are globally less effective for alkenes because of the overall inferior reactivity of allylic radicals towards $\mathrm{O}_{2}$ addition and following indirect branching. In the case of 3-hexene, the allylic 3-hexen-2-yl radical will be readily formed. This is true to some extent for all species that are likely to form resonance stabilized radicals, e.g. aromatics. Finally, because of the prominence of $\mathrm{HO}_{2}$ radicals and the easy formation of allylic radicals, the formation of alkadienes through second hydrogen abstraction is easy for 3-hexene and represents a vast proportion of the reactivity [20]. This reaction is exothermic and will therefore facilitate intermediate temperature branching through Reaction (R1). 

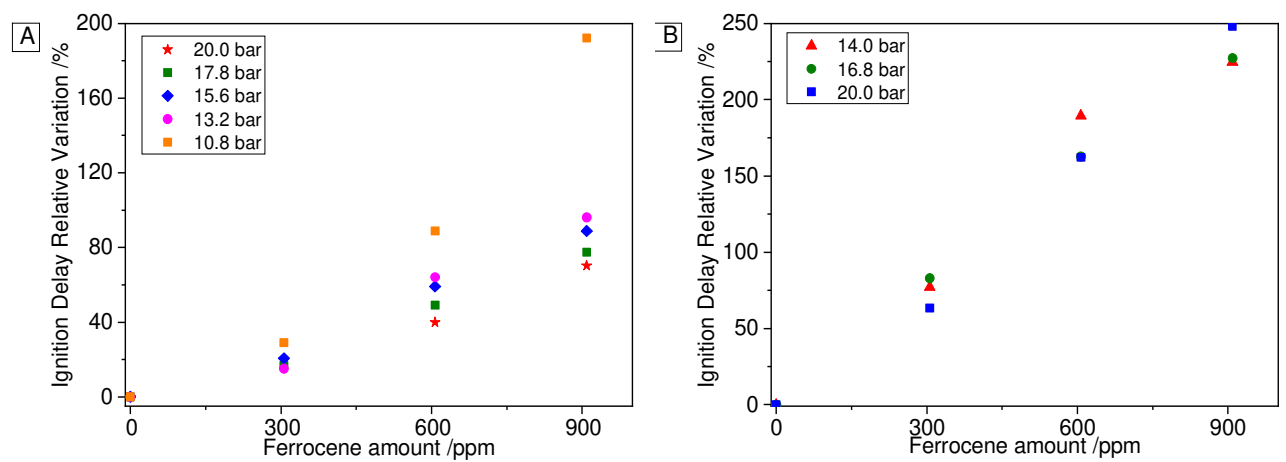

Figure 6: Relative variation of the ignition delay due to ferrocene addition to 3-hexene as a function of the compressed pressure $p_{\text {TDC. }} \mathrm{T}_{\mathrm{C}}=700 \mathrm{~K}(\mathrm{~A}), \mathrm{T}_{\mathrm{C}}=850 \mathrm{~K}(\mathrm{~B}) . \Phi=1$.

Again, $\mathrm{HO}_{2}$-inhibiting pathways are likely to postpone ignition. These results therefore further confirm the hypothesis of $\mathrm{HO}_{2}$ and $\mathrm{H}_{2} \mathrm{O}_{2}$ inhibition by iron oxide particles when ferrocene is added to the fuel.

\section{Simulations}

In order to provide further insight into these results and allow qualitative description of the effect of ferrocene, a submechanism describing the decomposition of ferrocene and reactivity of iron oxides particles was built, and added to the LLNL kinetic mechanism of gasoline surrogate fuels [32], which contains submechanisms for isooctane and 3-hexene. The ferrocene submechanism consists of the ferrocene thermal decomposition pathway, adopting the rate constant suggested by Lewis et al. [33], as well as addition reactions of $\mathrm{OH}, \mathrm{HO}_{2}, \mathrm{O}$ and $\mathrm{H}$ on ferrocene, since the cyclopentadienyl groups are sensitive to radical addition on double bonds. Rate constants for the addition reaction of $\mathrm{O}$ and $\mathrm{H}$ were proposed by Hirasawa et al. [9], with reaction rates close to the ones observed for alkenes [34], while the reaction rate for the addition of $\mathrm{OH}$ is adopted from Tsang [34]. For the addition of $\mathrm{HO}_{2}$, the reaction rate published by Stark [35] was used. These addition reactions on one of the cyclopentadienyl groups of ferrocene lead to the formation of iron cyclopentadienyl $\left(\mathrm{FeC}_{5} \mathrm{H}_{5}\right)$ and another product. The rate constant for the thermal decomposition of $\mathrm{FeC}_{5} \mathrm{H}_{5}$ was also given by Hirasawa et al. [9]. The addition reaction rates used for ferrocene were applied in the case of $\mathrm{FeC}_{5} \mathrm{H}_{5}$, reduced by a factor of two. A cyclopentadienyl submechanism was already included in the LLNL model. The oxidation of iron atoms, as described by Hirasawa et al. [9], was included with four 
reactions leading to iron oxide formation. However, the reaction rate for the reaction $\mathrm{Fe}+\mathrm{O}+\mathrm{M}=\mathrm{FeO}+$ $M$ exceeded the limit calculated from the collision theory [36], and was therefore reduced to its collision limit, without modification of the performance of the model. Finally, with respect to the simulation work of Pitz and Westbrook [16] for TEL, two reactions of $\mathrm{HO}_{2}$ radical and $\mathrm{H}_{2} \mathrm{O}_{2}$ on the surface of iron oxide particles were added. Reaction rates are estimated from the kinetic theory of gases:

$$
k_{\text {surf }}=\Gamma(\operatorname{surf} / \text { vol }) \sqrt{(k T / 2 \pi m)}
$$

Where $\Gamma$ is the surface efficiency; surf/vol is the developed surface of particle per unit of gas volume; $m$ is the mass of the interacting gaseous species. Several assumptions were made in order to simplify the calculation of $k_{\text {surf }}$. The rate of diffusion of gaseous species through the surrounding gases is not limiting. Also, the particles are supposed to be spherical with a constant diameter during the range of time of the simulation. For $\mathrm{HO}_{2}$ and $\mathrm{H}_{2} \mathrm{O}_{2}, \Gamma$, the surface efficiency, is taken to be unity, as was estimated by Pitz and Westbrook [16] in the case of TEL. The diameter of iron oxide particles was estimated to be $2 \mathrm{~nm}$ [27].

It results a succinct sub-mechanism of 16 reactions involving 6 iron-containing species, which is included as supplementary material. Simulations were performed with the sub-routine SENKIN from the Chemkin II package in constant volume conditions, as in the original validation of the LLNL model. It should be pointed out here that this modeling does not aim at providing an in length description of ferrocene reactivity in other conditions than those reached in this study, but rather to further test the hypothesis of an effect on $\mathrm{HO}_{2}$ and $\mathrm{H}_{2} \mathrm{O}_{2}$ with help from kinetic modeling. A more detailed study would require state-of-the-art calculation of reaction rate constants, as well as proper description of the particulate matter, and is beyond the scope of this study. Figures $7 \mathrm{a}$ and $\mathrm{b}$ depict the performance of the model.
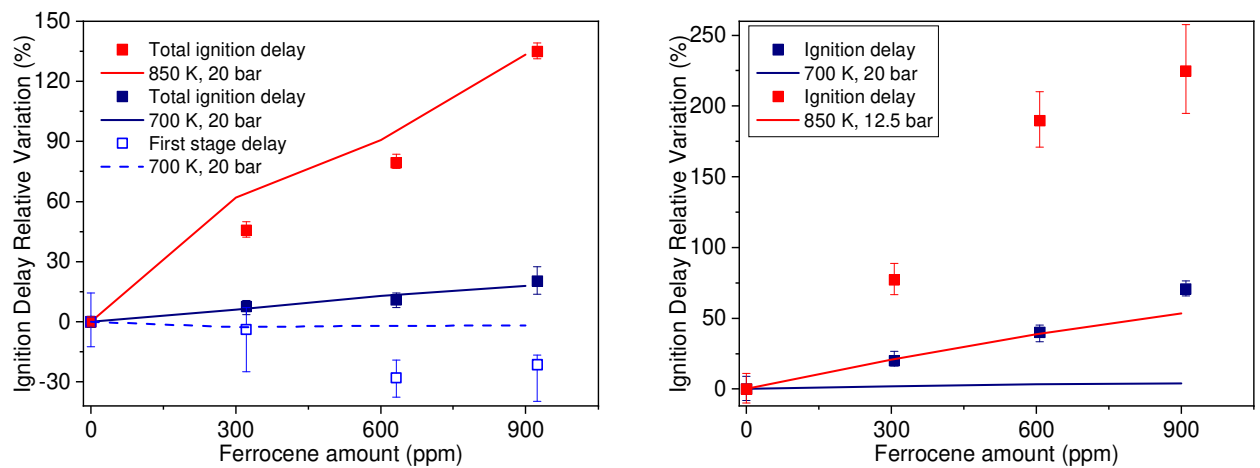
Figure 7: Comparison between simulated (lines) and experimental (symbols) relative variation of the total (full symbols and lines) and first-stage (open symbols, dashed line) ignition delay of stoichiometric fuel/ synthetic air mixtures due to ferrocene. (A) isooctane $/ \mathrm{O}_{2} /$ inert mixtures, (B) 3-hexene $/ \mathrm{O}_{2} /$ inert mixtures.

Figure 7 presents the experimental and modeled relative variations of the ignition delay with ferrocene addition. Results are shown for both isooctane and 3-hexene at 700 and $850 \mathrm{~K}$, at the highest top dead center pressure where ignition delays could be measured for each condition. Error bars are added to the experiments, evaluating the effect of the normalization process. In the case of isooctane first-stage ignition, this uncertainty can be high because of the low ignition delay values. The limited effect of ferrocene on first stage ignition delays is captured, and the evolution of the total ignition delay is in agreement with the experiments. However, this effect is significantly under-estimated in the case of the 3-hexene experiments. Nevertheless, it is worth emphasizing that the model provides qualitative agreement on the effect of ferrocene in both cases (Fig. 7); the addition of ferrocene always increases the ignition delays, and this increase is monotonic with the mole fraction of ferrocene. The observed disagreement in the case of 3-hexene could result from missing reaction pathways involving $\mathrm{HO}_{2}$ or $\mathrm{H}_{2} \mathrm{O}_{2}$ in the ferrocene decomposition mechanism. The hereby developed mechanism was also tested in conditions relevant to a previous study [15], where atomic iron was added to $n$ heptane/air mixtures. The model predicts a reduction of the ignition delay when iron atoms are added, as suggested in [15]. This could be a consequence of the highest extent of Low Temperature reactivity in the case of $n$-heptane, in comparison with isooctane and 3-hexene.

\section{Conclusions}

The effect of ferrocene on the ignition delays of stoichiometric fuel $/ \mathrm{O}_{2} /$ inert mixtures was experimentally investigated with the ULille RCM, at pressures from 6 to 20 bar, core gas temperatures of 700 and $850 \mathrm{~K}$, and mole fractions of ferrocene up to $900 \mathrm{ppm}$. Fuels selected were isooctane and 3-hexene, in order to investigate the effect of this octane booster in the case of fuels with significantly different reactivity patterns. From the experimental results, the addition of ferrocene shows:

- A clear increase of the ignition delay in all conditions. In the case of two-stage ignition, the effect on the first stage ignition delay is limited, and lies mostly in an increase of the second stage of the ignition delay. 
- A monotonic increase of the ignition delay with the amount of ferrocene.

- $\quad$ No loss of effectiveness while increasing the mole fraction of ferrocene up to $900 \mathrm{ppm}$.

- Highest effect in the case of fuels with limited negative temperature coefficient behavior, where $\mathrm{HO}_{2}$ addition reactions are of importance.

These experimental observations concur with the suggestion from Pitz and Westbrook [16] that the mode of action of organometallics on ignition delays lies in an inhibition of $\mathrm{HO}_{2}$ and $\mathrm{H}_{2} \mathrm{O}_{2}$, with little to no effect on $\mathrm{OH}$ radicals. The oxidation of ferrocene yields gaseous iron that rapidly oxidizes into gaseous iron oxides, which aggregate into particles. On the surface of iron oxide particles, $\mathrm{HO}_{2}$ and $\mathrm{H}_{2} \mathrm{O}_{2}$ are converted onto unreactive species.

With respect to this kinetic insight, a 16-reactions kinetic sub-mechanism of the oxidation of ferrocene in the low temperature combustion range of temperature was developed. This sub-mechanism was coupled with a gasoline surrogate model, and yielded qualitative description of the anti-knock effect of ferrocene. While it would be risky to extrapolate on other organometallic octane boosters, the present results suggest that the ability of such molecules to lose their organic moiety, and form oxide particles is one of their most important features. This correlates with the fact that the nature of the metallic atom in such molecules has larger influence on their antiknock properties than the structure of their organic part. This work could therefore be extended to other organo-metallic octane boosters, provided that their decomposition mechanisms are understood.

\section{Acknowledgements}

This work has been funded by Total Marketing Services.

\section{Supplementary Material}

Ferrocene sub-mechanism, in Chemkin format.

Table of the measured and simulated ignition delays. 


\section{References}

[1] T. Midgley, T.. Boyd, J Ind Eng Chem 14 (1922) 894-898.

[2] P.A. Bonczyk, Combust. Flame 87 (1991) 233-244.

[3] J.B.A. Mitchell, Combust. Flame 86 (1991) 179-184.

[4] J. Zhang, C.M. Megaridis, Combust. Flame 105 (1996) 528-540.

[5] D.J. Wallis, N.D. Browning, C.M. Megaridis, P.D. Nellist, J. Microsc. 184 (1996) 185-194.

[6] U. Matter, K. Siegmann, J. Aerosol Sci. 28 (1997) S51-S52.

[7] M. Kasper, K. Sattler, K. Siegmann, U. Matter, H.C. Siegmann, J. Aerosol Sci. 30 (1999) 217225.

[8] J.B.A. Mitchell, J.L. LeGarrec, G. Saidani, F. Lefeuvre, S. di Stasio, Energy Fuels 27 (2013) 4891-4898.

[9] T. Hirasawa, C.-J. Sung, Z. Yang, A. Joshi, H. Wang, Combust. Flame 139 (2004) 288-299.

[10] G.T. Linteris, M.D. Rumminger, V. Babushok, W. Tsang, Proc. Combust. Inst. 28 (2000) 2965-2972.

[11] G.T. Linteris, V.. Katta, F. Takahashi, Combust. Flame 138 (2004) 78-96.

[12] G.T. Linteris, M.D. Rumminger, V.I. Babushok, Prog. Energy Combust. Sci. 34 (2008) 288329.

[13] M.D. Rumminger, D. Reinelt, V. Babushok, G.T. Linteris, Combust. Flame 116 (1999) 207219.

[14] K. Tian, Z.S. Li, S. Staude, B. Li, Z.W. Sun, A. Lantz, M. Aldén, B. Atakan, Proc. Combust. Inst. 32 (2009) 445-452.

[15] M. Zhu, Z. Zhang, D. Zhang, Energy Fuels 31 (2017) 2190-2197.

[16] W.J. Pitz, C.K. Westbrook, Combust. Flame 63 (1986) 113-133.

[17] R. Minetti, M. Carlier, M. Ribaucour, E. Therssen, L.R. Sochet, in: Symp. Int. Combust., Elsevier, 1996, pp. 747-753.

[18] H.J. Curran, P. Gaffuri, W.J. Pitz, C.K. Westbrook, Combust. Flame 129 (2002) 253-280.

[19] M. Mehl, G. Vanhove, W.J. Pitz, E. Ranzi, Combust. Flame 155 (2008) 756-772.

[20] G. Vanhove, M. Ribaucour, R. Minetti, Proc. Combust. Inst. 30 (2005) 1065-1072.

[21] Y. Yu, G. Vanhove, J.F. Griffiths, S. De Ferrières, J.-F. Pauwels, Energy Fuels 27 (2013) 3988-3996.

[22] Y. Fenard, M.A. Boumehdi, G. Vanhove, Combust. Flame 178 (2017) 168-181.

[23] M. Fulem, K. Růžička, C. Červinka, M.A.A. Rocha, L.M.N.B.F. Santos, R.F. Berg, J. Chem. Thermodyn. 57 (2013) 530-540.

[24] D. Lee, S. Hochgreb, Combust. Flame 114 (1998) 531-545.

[25] G. Vanhove, G. Petit, R. Minetti, Combust. Flame 145 (2006) 521-532.

[26] F. Battin-Leclerc, Prog. Energy Combust. Sci. 34 (2008) 440-498.

[27] I. Wlokas, A. Faccinetto, B. Tribalet, C. Schulz, A. Kempf, Int. J. Chem. Kinet. 45 (2013) 487498.

[28] X. Meng, A. Rodriguez, O. Herbinet, T. Wang, F. Battin-Leclerc, Combust. Flame 181 (2017) 283-299.

[29] S.M. Burke, W. Metcalfe, O. Herbinet, F. Battin-Leclerc, F.M. Haas, J. Santner, F.L. Dryer, H.J. Curran, Combust. Flame 161 (2014) 2765-2784.

[30] D.J. Ray, A. Redfearn, D.J. Waddington, J. Chem. Soc. Perkin Trans. 2 (1973) 540-543.

[31] R.R. Baldwin, R.W. Walker, in: Eighteenth Symp. Int. Combust., Elsevier, 1981, pp. 819-829.

[32] M. Mehl, W.J. Pitz, C.K. Westbrook, H.J. Curran, Proc. Combust. Inst. 33 (2011) 193-200.

[33] K.E. Lewis, G.P. Smith, J. Am. Chem. Soc. 106 (1984) 4650-4651.

[34] W. Tsang, J. Phys. Chem. Ref. Data 20 (1991) 221-273.

[35] M.S. Stark, J. Am. Chem. Soc. 122 (2000) 4162-4170.

[36] D. Chen, K. Wang, H. Wang, Combust. Flame 186 (2017) 208-210. 


\section{Figure captions}

Figure 1: Pressure profiles during the two-stage ignition of isooctane/ferrocene/synthetic air mixtures and associated non-reactive pressure trace. $\Phi=1, p_{\mathrm{TDC}}=1.56 \mathrm{MPa}, \mathrm{T}_{\mathrm{C}}=700 \mathrm{~K}$.

Figure 2: Evolution of total ignition delays as a function of pressure for isooctane/ferrocene $/ \mathrm{O}_{2} / \mathrm{Ar}$ mixtures. $\Phi=1,(\mathrm{~A}) \mathrm{T}_{\mathrm{C}}=700 \mathrm{~K} ;(\mathrm{B}) \mathrm{T}_{\mathrm{C}}=850 \mathrm{~K}$.

Figure 3: Relative variation of the ignition delay due to ferrocene addition to isooctane as a function of the compressed pressure $p_{\text {TDC }} \Phi=1$. (A) $\mathrm{T}_{\mathrm{C}}=700 \mathrm{~K},(\mathrm{~B}) \mathrm{T}_{\mathrm{C}}=850 \mathrm{~K}$.

Figure 4: Pressure profiles during the ignition of 3-hexene/ferrocene/synthetic air mixtures. $\Phi=1, p_{\mathrm{TDC}}=$ $1.52 \mathrm{MPa}, \mathrm{T}_{\mathrm{C}}=700 \mathrm{~K}$.

Figure 5: Evolution of total ignition delays as a function of pressure for 3-hexene/ferrocene $/ \mathrm{O}_{2} / \mathrm{Ar}$ mixtures. $\Phi=1,(\mathrm{~A}) \mathrm{T}_{\mathrm{C}}=700 \mathrm{~K} .(\mathrm{B}) \mathrm{T}_{\mathrm{C}}=850 \mathrm{~K}$.

Figure 6: Relative variation of the ignition delay due to ferrocene addition to 3-hexene as a function of the compressed pressure $p_{\text {TDC. }} \mathrm{T}_{\mathrm{C}}=700 \mathrm{~K}(\mathrm{~A}), \mathrm{T}_{\mathrm{C}}=850 \mathrm{~K}(\mathrm{~B}) . \Phi=1$.

Figure 7: Comparison between simulated (lines) and experimental (symbols) relative variation of the total (full symbols and lines) and first-stage (open symbols, dashed line) ignition delay of stoichiometric fuel/ synthetic air mixtures due to ferrocene. (A) isooctane/ $\mathrm{O}_{2} /$ inert mixtures, (B) 3-hexene $/ \mathrm{O}_{2} /$ inert mixtures. 